\title{
GUERRA SINALÉTICA NOS TERMOS DE BAUDRILLARD: INSURREIÇÃo PELOS SIGNOS
}

\author{
[SIGNALETIC WAR ACCORDING TO BAUDRILLARD’ TERMS: INSURRECTION BY SIGNS]
}

\author{
Rodrigo Amorim Castelo Branco * \\ Universidade de Brasília, Brasil
}

\begin{abstract}
Resumo: Como se faz uma guerra? Esta é a pergunta essencial do texto que aqui é desenvolvido acerca do pensamento político de Baudrillard, sobretudo a partir da obra intitulada $A$ troca simbólica e a morte (L'échange symbolique et la mort, 1976). Uma resposta introdutória à questão colocada indica que guerras, nos tempos vigentes, superam o princípio de realidade a partir do uso de simulações, o que indica a construção de uma era hiper-real. O capital e os seus signos se desacoplam do mundo da representação e essa mudança no interior do sistema afeta diretamente o trabalho, que se dissemina na sociedade após perder o seu caráter fabril. Baudrillard, desde a década de 70, anuncia que o modo de guerrear politicamente volatilizouse de forma tão ampla, que os embates atuais precisam se direcionar contra o capital sinalético. $\mathrm{O}$ objetivo deste texto, nesse sentido, é discutir e exemplificar modos de insurgência guiados por simulações e por dispersão de signos.
\end{abstract}

Palavras-ChaVe: Hiper-realidade; Simulação; Sinalético; Capital; Guerra
ABstract: How to make war? This is the essential question of the text developed here regarding Baudrillard's political thought, especially from the work entitled Symbolic Exchange and Death (L'échange symbolique et la mort, 1976). An introductory answer to the question posed above indicates that wars, in current times, surpass the principle of reality through the use of simulations, which indicates the construction of a hyper-real era. The capital and its signs are detached from the world of representation and this change within the system directly affects work, which spreads itself in society after losing its factory character. Since the 1970s, Baudrillard has announced that the way to war politically has become volatile so widely that the current conflicts need to be directed against the signaletic capital. In this meaning, the purpose of this text is to discuss and exemplify insurgency modes guided by simulations and dispersion of signs.

KEYwORDS: Hyper-reality; Simulation; Signaletic; Capital; War.

\section{Perspectivas do TeXto}

— mbora o diagnóstico de Baudrillard acerca das operações do capital abordado

- neste texto tenha embasamento em suas obras lançadas nas últimas décadas do século passado, as discussões do mencionado autor sobre o império sígnico ou sinalético (ordem dos signos) apresentam-se fecundas para tentarmos compreender o esquema hiper-real que rege a sociedade e a cultura no tempo vigente. Os modos de

* Doutorando do Programa de Pós-Graduação em Filosofia da Universidade de Brasília - UnB e Mestre em Filosofia pela mesma Universidade. E-mail: rodrigocasbranco@gmail.com 
embates políticos e os signos que hoje exacerbam a realidade, engendrando excesso de informações, imagens e múltiplas simulações se tornam temas especiais de uma epocalidade histórica em que o poderio sígnico não dominou a existência completamente, todavia, caminha em ritmo acelerado e maximiza a sua força cotidianamente. Por isso a relevância de refletir sobre as categorias pensadas por

104 Baudrillard como hiper-realidade e simulação, tendo-se a percepção de como o trabalho está envolvido em um modo de disseminação de ocupações que transforma o sujeito em um ganhador de autogestão, mas, sincronicamente, o faz perdedor de vida particular, o que chamamos, neste texto, de hiper-realização trabalhista.

A segunda perspectiva do texto é, a partir das reflexões sinaléticas de Baudrillard, evidenciar formas de fazer frente à volatização e arreferencialidade do capital que, por sua ilegibilidade ficcional, consegue penetrar as várias esferas sociais, mas, ao mesmo tempo, esfumaça-se na flutuação do signo.

Se, no primeiro momento deste escrito, o assunto principal é a lógica do capital, o modo como ele gera simulações e se torna o elemento operatório econômico, político e sociocultural, a seção seguinte discute os contrapontos possíveis ao sistema, utilizando as suas próprias condições e mecanismos arreferenciais. A ótica é usar a sua lógica de derretimento e de flutuação para fortalecer, sinaleticamente, os movimentos insurgentes que ainda se apegam, unicamente, à política de marcadores para reivindicar e sublevar contra o que está instituído. Para Baudrillard, a guerra situada ou lastreada por definições, vias e respostas dadas perde lugar nos tempos hodiernos. E se não se leva em conta esse diagnóstico, os segmentos antissistema apenas alimentarão a ordem imposta pelo capital.

Para complementar a reflexão aqui proposta acerca de como proceder antiteticamente ao império do sistema, apresentamos exemplos sobre a eficácia da guerra sinalética, que pode violentar por desorientação sem perspectiva de gastos estrondosos assim como se prodigaliza em um conflito concreto. A chave baudrillardiana é fazer da contra-hermenêutica, da dispersão anagramática e da quebra com a representação - que podemos encontrar no poético, nos graffiti e na transmutação de signos orientadores do real -, as hiper-forças contra o capital, este que vive da mesma ordem sígnica. De fato, para Baudrillard, trata-se da guerra contra a guerra. A revolução só tem espaço na luta simbólica, ausente de presenças ou equivalentes. Sabendo disso, a questão é uma mudança de postura dos segmentos micropolíticos: a insurreição pelos signos.

\section{TrabalHo, HiPER-REALIDADE E SIMULAÇÃo NA LÓGICA DO CAPITAL}

O pensamento político de Baudrillard anuncia (1996, p. 8): "Hoje, todo o sistema oscila na indeterminação, toda realidade é absorvida pela hiper-realidade do código e da simulação. É um princípio de simulação que nos rege doravante em lugar do antigo princípio de realidade. As finalidades desapareceram". A partir dessa reflexão, Baudrillard traz à luz a volatilidade com a qual os contemporâneos convivem e conviverão continuamente: a era da arreferencialidade chegou e perdurará. O que tal diagnóstico de época significa? Indica que construções artísticas, culturais, sociais e políticas que tinham equivalente real, perdem vigor na grande estrutura sinalética que o capital satura com a construção de hiper-realidades, dispersando-se da vida concreta. Isso indica o quanto a semiocracia se torna a linha mestra que suplanta a representação em direção à simulação. Nesse sentido, se as construções sistêmicas não mais se ancoram em representações, mas em simulacros, a vida planetária se transforma no colossal projeto de exacerbação do real. Passam a existir inflação antes nunca vista de reprodutibilidade técnica, imagens, publicidade, "inovações", modas, marketing, formas 
de trabalho, virtualidades e digitalidades. No meio de todo esse aparato estrutural suplementar de signos, há o acréscimo de simulações.

A maquinaria simbólica que hoje perdura, simula a existência a partir da reprodução de cópias que suplantam o real e até mesmo fazem dos simulacros originalidades. Há uma espécie de kitschficação ${ }^{1}$ do mundo na era da reprodutibilidade técnica, permitindo que o reproduzido se torne mais chamativo e verdadeiro do que o conteúdo original. Isso acontece, frequentemente, com uma fotografia ímpar que, ao ser reproduzida, torna-se simulacro na sociedade de consumo ou na excessiva dispersão informativa dos meios de comunicação em rede. Ou seja, profusão de signos e de "informações", sem vínculo representativo com o mundo, indica produção de hiperrealidade. "Na análise de Jean Baudrillard, com a proliferação de imagens que caracteriza o cenário cultural contemporâneo, os signos não remetem mais a referentes "reais", mas simplesmente a outros signos - representações de representações ou simulacros: vivemos no reino da hiper-realidade" (SILVA, 2000, p. 100).

A motivação para a criação e maximização, ano após ano, da ordem hiper-real advém do código do capital que flutua em indeterminação. Embora Baudrillard afirme que (1996, p. 8) “Já não há ideologia; há apenas simulacros" (Il n’y a plus d'idéologie, il n'y a plus que des simulacres) no esquema hiper-real, a sua aleatoriedade tem um fundamento político definido: fazer do capital o elemento operatório tão flutuante, que a tudo domine sem ser dominado; que gere incumbências massivas à sociedade trabalhadora, mas que não seja encontrado em lugar algum para apresentar respostas ou motivações ao público. Assim, o projeto de emancipação europeu do século XVII, sequioso por autonomia - que hoje se desenvolve na chamada era "pós-moderna" implica justamente na maximização de uma espécie de sinaleticidade aleatória a ponto de lançar o sujeito à sua própria sorte. É o que acontece, por exemplo, com o trabalhador. O capital se torna autônomo e o heterônomo (corpo social) está jogado como empreendedor sem vínculo empregatício. O trabalhador é dono de si e depende de seu próprio desempenho. Surge a rasa ideia social de que estar empregado, hoje, é um exercício de liberdade. O grande problema é definir o que é trabalho e o que é vida privada, uma vez que, na epocalidade do desempenho, os dois se confundem e até mesmo o primeiro invade a segunda. Para Baudrillard, na seção Trabalho (Le travail) da obra A troca simbólica e a morte (L'échange symbolique et la mort, 1976), a hiperrealização do trabalho produz "horários variáveis, mobilidade, reciclagem, formação permanente, autonomia, autogestão, descentralização do processo de trabalho [...] emprego personalizado [...] A força de trabalho já não é vendida nem comprada brutalmente; ela é projetada, é anunciada" (BAUDRILLARD, 1996, p. 24).

O que Baudrillard evidencia é o processo semiúrgico a partir do qual a produção sucursal perde vigor com o paulatino desaparecimento dos locais, sujeitos e tempos comuns de trabalho. A fábrica passa a ser preterida. A própria sociedade estreia como ambientação trabalhista, uma vez que agora, sem filial, precisa que assuma o caráter da fábrica, autoproduza e desempenhe papéis se inventando e reinventando na epocalidade em que os sujeitos se tornaram sucursais: um tipo de fábrica em ambiente privado. Nesse panorama de pulverização de labor, diz Baudrillard (1996, p. 29): "O trabalho está em toda parte porque já não existe trabalho" (Le travail est partout, parce qu'il n'y a plus de travail). Isto é, a partir da crescente extinção das fábricas com seus grandes galpões, o trabalho se hiper-realiza, expande-se, volatiliza-se e a responsabilidade para criar todos os recursos de atuação é do próprio "trabalhador", uma vez que não encontra o meio sucursal que garanta mecanismos produtivos e nem sequer direitos trabalhistas. Podemos dizer, assim, que na era sinalética, o trabalhador está só e sem desculpas. É artífice de si mesmo. O trabalho é disseminado diariamente por meio de celulares e notebooks, fazendo do sujeito atuante, inserido na malha dessa pulverização de ocupações, um autogestor em meio à política do labor generalizado. O jugo trabalhista 
passa a controlar o corpo social sem precedentes.

Antes, o termo "desempenho" foi citado em referência ao trabalho que se alastra socialmente e faz dos cidadãos autogestores. Trata-se de uma palavra amplamente discutida na obra Sociedade do cansaço (Müdigkeitsgesellschaft, 2010) de Chul Han, autor que, em seu texto, dialoga com Baudrillard. Chul Han se refere ao excesso de positividade de uma sociedade que não está mais sob a égide da negatividade disciplinar das instituições que obrigavam certos tipos de condutas. Troca-se a lei, o ordenamento e a coibição pela motivação, iniciativa e atuação ininterrupta. Quanto mais se estimula psicologicamente o sujeito, mais se hiper-realiza o trabalho. Assim, a disciplina que opera a partir do poder do "não" no prisma reflexivo de Michel Foucault, para Chul Han, perde vigência em uma sociedade na qual tudo pode ser feito, nada sendo impossível para os motivados a fazer acontecer os seus projetos. O filósofo sulcoreano dá, como exemplo, a motivação plural da frase presidencial Yes, we can! E Just do it é a frase positiva que hoje estampa as camisas de muitos que assimilaram rápido o imperativo mundial do desempenho.

Segundo Chul Han, o capital desenvolve-se para além da disciplina porque leva em conta que lançar o trabalhador à sua "liberdade" de atuação é mais significativo do que aplicar a negatividade da obrigação. Essa perspectiva liberal de trabalho entende que o sujeito positivo ou sujeito de desempenho é mais aplicado, eficiente e ágil na produção do que o sujeito negativo modulado por leis. É aqui que se instaura uma sociedade da iniciativa pessoal, da autogestão, do esforço singular. É esse excesso de positividade (tudo pode ser feito) que desenvolve a doença do nosso século: o cansaço neuronal, desempenho como um novo mandato da sociedade pós-moderna do trabalho" (CHUL HAN, 2017, p. 27).

Assim como esclarece Baudrillard, o movimento hiper-real de labor se torna uma espécie de retotalização do trabalho que faz o indivíduo ter a sua esfera de vida pessoal invadida pela positividade que motiva a atuação profissional. Para Chul Han, trata-se de um modo de autoexploração enquanto o trabalhador pensa estar livre para desempenhar o seu papel sem negatividades (ausência de coerções hierárquicas). Ao contrário, quanto mais autorreferencial é a atividade do trabalhador, mais contraditória é a sua liberdade, porque surge um ego hiperativo, emerge uma vida ativa que desconhece uma vida contemplativa, já que o indivíduo se torna um animal laborans (animal trabalhador), um explorador de si mesmo. Nesse sentido, quando o profissional consome o pessoal, até mesmo o lazer é afetado pela ordem positiva do trabalho. Baudrillard sabe muito bem disso (1996, p. 24): "O trabalho (também sob a forma de lazer) invade toda a vida como repressão fundamental, como controle, como ocupação permanente em lugares e tempos regulados".

O trabalho constrange frequentemente, nunca para porque está hiper-realizado, disseminado pelas redes. As corporações hiper-reais atuam para além da produção sucursal. As pessoas podem criar lojas virtuais para operar venda de artigos. A possibilidade de se trabalhar como empreendedor individual também é o que permite a ausência de tempo particular. Como salienta Baudrillard, o sistema constrange o trabalho mesmo diante de seu tempo "livre". O constrangimento se dá nas várias ocasiões ou ambientes. Tirou-se tempo de descanso e se está na praia, mas "As leis do sistema (de produção) nunca entram em férias (BAUDRILLARD, 1995, p. 163). Isso demonstra o quanto o capital se torna um modelo que dissemina demandas e responsabilidades às pessoas para além dos limites profissionais. Impulsiona a era planetária do ego hiperativo e do estímulo ao labor, do ser-ativo em qualquer circunstância. O capital se volatiza a ponto de se encontrar em toda a vida particular, incumbe e cobra tarefas múltiplas, gerando instrumentos estimulantes de trabalho.

Com o fortalecimento do virtual/digital, perde-se cada vez mais equivalências e conexões com o real. O signo, engendrado por simulação, não se baseia em condições 
concretas, perde o lastro, o seu garantidor de realidade, o seu equivalente representativo. Valor de uso e de troca, ou seja, finalidade de produtos e bens de mercado perdem vigor na era sinalética e entra em cena a ordem arreferencial. "É o outro estágio do valor que prevalece sobre ele, o da relatividade total, da comutação geral, combinatória e simulação. Simulação no sentido de que todos os signos se trocam doravante entre si sem nenhuma troca contra o real" (BAUDRILLARD, 1996, p. 16). Simular, como esclarece Baudrillard, indica que não se faz mais necessário vínculo com a atualidade empírica para se criar. A simulação está desgarrada do real não para degradá-lo, mas para gerar-se realidade em demasia. Surgem modelos digitais para tanto, que podem edificar hologramas, virtualidades, técnicas e artificialidades sem estarem lastreadas por qualquer condição a posteriori. A simulação, sem lastro, não tem limites e se torna o modelo de si mesmo, podendo simular para além de uma reserva permanente. Essa reserva não existe, por isso a hiper-realidade "realiza", digitalmente, sem uma medida definida.

A análise semiológica de Baudrillard evidencia que, em uma condição planetária hiper-real, o signo de tornou autônomo, dado que não está mais na zona da representação para se gerar equivalência ou correção. As operações deixam de ter que designar o concreto, porque o jogo estrutural de combinações extra-real permite se criar imagens antes mesmo que a existência as projete. A simulação antecipa o real. Surge a era em que as marcas e imagens têm mais importância do que os seus produtos lançados; a imagem acontece antes de um alicerce empírico. A obrigação do signo de referenciar uma realidade equivalente no mundo fáctico se torna anacrônica e, assim, legaliza-se a sinalética indiferente e flutuante. Isso se dá no meio midiático (anúncios que inflacionam informações, desgarram-se do real e criam um mundo-efígie); no meio econômico (o fím do padrão-ouro da moeda quando se rompe com o seu lastro disciplinador); no meio político (leis discutidas e aprovadas no parlamento sem referência ao lastro real chamado poder originário popular); no meio trabalhista (o trabalho flutua, dissemina-se para todos, invade a vida privada, colocando o sujeito na dimensão do desempenho constante). Há muita informação, difusão de "novidades", todavia, há grande tensão em se definir a realidade do que se maximiza para a sociedade. Aí a grande preocupação com as eleições futuras, tendo-se em vista que a hiper-realização (simulação) de notícias, estas sem qualquer ancoragem no mundo da vida, é o que gerará tensão política. Acerca de algumas das questões aqui elencadas, Baudrillard elucida, na seção $A$ revolução estrutural do valor (La révolution structurale de la valeur):

A flutuação das moedas e dos signos, a flutuação das "necessidades" e das finalidades de produção, a flutuação do próprio trabalho - a comutabilidade de todos os termos que se acompanha de uma especulação e de uma inflação sem limites (está-se, de fato, na liberdade total - desafeição, desobrigação, desencanto geral [...]; o capital libertou os signos dessa "ingenuidade" para os lançar na circulação pura (BAUDRILLARD, 1996, p. 16, grifos do autor).

O capital, a cada progresso econômico, aprioriza-se, mais se maquina na desenfreada busca pela pureza (volatização hiper-real). Capital puro assinala um sistema operatório flutuador e patriarca do jogo sígnico de especulação que o estimula a romper cada vez mais com equivalentes reais. É como se ele tivesse como projeto se transformar em uma vontade geral apriorista, sobrehumana, que a tudo comanda sob a base teleológica arreferencial. Assim, "A determinação está morta; a indeterminação reina. Houve uma ex-terminação (no sentido literal do termo) dos reais de produção, do real de significação" (BAUDRILLARD, 1996, p. 16), porque a revolução estrutural do valor cria a ordem hiper-real, da emancipação do signo, da quebra com a equivalência a conteúdos situados. Revolução do capital, aqui, inclina-se à desterritorialização, à des- 
marcação de itinerários.

No prisma reflexivo de Baudrillard, é o capital mesmo que extingue as determinações sociopolíticas, comandando todo o planejamento flutuante do sistema. É justo esta operação sígnica, corruptora de marcadores, que permite simulacros, propiciando a fusão e a confusão de ideias e de vivências. Vertentes políticas, perspectiva de verdadeiro e falso, variabilidade do que é útil ou não, extrema dificuldade em julgar o que é moral, estético e justo, tudo isso se tornou litigante como nunca antes, uma vez que a flutuação de concepções rumo à indiferença toma lugar na conjuntura social e cultural dos contemporâneos. "Trata-se do bordel generalizado do capital [...] de substituição e de comutação" (BAUDRILLARD, 1996, p. 18) (C'est ça le bordel généralisé du capital [...] de substitution et de commutation). Substitui-se rapidamente ideias, humanos (como peças), perspectivas e modos de atuação. Para quê? Por quê? Quanto mais comutação, mais hiper-realidade. Maximiza-se, assim, a indecidibilidade social e menos ancoragem há em um equivalente real para que possamos definir o que tem vigor de autenticidade entre as flutuantes "realidades" que cotidianamente nos afetam.

A lei estrutural do valor, que surge como resultado da ultrapassagem da lei de valor de uso e de valor de troca (estas últimas em perspectiva industrial e marxiana), corresponde à hiper-realidade ou, podemos dizer, à ordem do puro signo. Ela não tem em vista unicamente o progresso planetário a partir de simulações que são os modelos de si mesmas, já que se retroalimentam sem base referencial no meio circundante. Para Baudrillard, a lei estrutural do valor que rege e maximiza o hiper-real aceleradamente, representa um mecanismo de soberania cujos os princípios basilares de sua conduta dominante são pureza e ilegibilidade, elementos estes que não se firmam a partir de violência física, mas na arreferencialidade anuladora de marcadores revolucionários. Baudrillard, nesse sentido, elucida:

[...] o capital é um modo de dominação, encontramo-nos sempre bem aí, porque essa lei estrutural do valor é a forma de dominação social mais pura, ilegível, como a mais-valia, sem referências, doravante, numa classe dominante ou numa relação de forças, sem violência, inteiramente absorvida sem vestígios de sangue nos signos que nos cercam, em toda parte operacional no código onde o capital tem, enfim, seu discurso mais puro, para além dos dialetos industriais, de mercado, financeiros, para além dos dialetos de classe [...] Violência simbólica inscrita, em toda parte, nos signos, e até nos signos da revolução (BAUDRILLARD, 1996, p. 20, grifos do autor).

Como anuncia a indicação, o capital regido pelo código formal (desacoplado do real), tem como trunfo maior a ilegibilidade, o que obseda e obscurece os seus projetos, tornando-se complexo interpretá-lo. O código intransparente do capital não permite, aos movimentos antípodas ao sistema, que estes consigam traçar planejamentos no mínimo razoáveis contra o hiper-real. Esta última consegue velar caminhos, anular reivindicações sem qualquer ato de violência que venha derramar sangue, uma vez que o capital entende que a guerra não está mais na dimensão dos artefatos e artimanhas físicas ou metafísicas, mas no arranjo sinalético. Assim, a melhor arma de luta do sistema não implica em conflitos corpo a corpo contra movimentos revolucionários. Em sinal de evolução bélico-sígnica, indica que a violência precisa existir, mas em prisma simbólico, indo além de representações funcionais (valores de uso e de troca). É quando se suplanta esses estágios que o capital ingressa na lei estrutural do valor e se aprioriza a ponto de se tornar uma invisibilidade hiper-real.

O problema de Baudrillard é como reagir contra o que se volatilizou em forma, perdendo o seu grau de conteúdo. Para ele, revertemos a ordem do sistema contra si ou utilizamos uma lógica ainda superior à forma-signo do capital, do contrário, a revolução 
estrutural do valor (formalização do capital) continuará anulando as bases da revolução popular. Enquanto as operações capitalistas se nutrem sinaleticamente, isto é, sem auxílio de referenciais legíveis, as micropolíticas ainda confiam a "revolução" a marcadores. Porém, "A perda de referenciais afeta mortalmente, de início, os referenciais revolucionários" (BAUDRILLARD, 1996, p. 20) (La perte des référentiels affecte mortellement d'abord les référentiels révolutionnaires). Isto é, o capital vive de simulações e quanto mais o faz, mais suspende revoluções, uma vez que o seu alimento formal e a extensão de sua pureza liquidam as contraposições (movimentos de libertação). Se as bases da revolução micropolítica não sofrerem transmutação, a perspectiva de Baudrillard é que elas servirão apenas como combustível para maior projeção da violência sígnico-formal do código onipresente.

No próximo momento deste texto, a discussão gira em torno de como o sistema atua a partir da superioridade sígnica. Logo após, tratamos dos movimentos que forjam práticas sinaléticas contra a formalidade do capital, demonstrando que a guerra simbólica é possível e, de alguns modos, já foi colocada em uso.

\section{GUERRA CONTRA A GUERRA: A INSURREIÇÃO SÍGNICA}

Diante de toda hiper-realidade hoje atuante que pulveriza trabalho e múltiplas simulações, a questão é: como guerrear contra um capital que se volatiza e invade a esfera privada dos indivíduos? Ele não permite que possamos respondê-lo, dado que o seu código se esfumaça e não o encontramos para o embate em pé de igualdade enquanto nos dispomos a lidar com referências. A resposta de Baudrillard é clara (1996, p. 10): "Não combatemos o aleatório a golpes de finalidade, não combatemos a dispersão programada e molecular a golpes de tomadas de consciência e de superações dialéticas, não combatemos o código a golpes de economia política nem de 'revolução"'. O que Baudrillard insinua é que guerra com marcadores perdeu espaço e não há futuro nela. Os antigos meios de revolta como passeatas, produção de cartazes que clamam por justiça e velhos itinerários de luta definidos por segmentos contrários à ordem política instaurada traçam uma linha significativa apenas para a cooptação por meio do código, que consegue planejar possíveis respostas aos que pensam revolucionar com as suas "armas".

O capital é simulador. Isso significa que ele projeta e hiper-realiza as suas tendências e vontades simbolicamente. Há o modelo sígnico que se autorreplica, uma espécie de DNA do capital pronto a reproduzir cultura, vida e sociedade como se estivesse remasterizando todas essas dimensões. A sua flutuação e arreferencialidade se conjugam em modelo para propiciar o domínio da forma-signo em prisma planetário. É por esta pureza formativa do capital que, para Baudrillard, o sistema não pode sofrer ataques contundentes por concentração de forças diretas, movimentos dialéticos, grupos partidários, o que apenas o estimula a se tornar mais amplo no esquema hiper-real. A perspectiva ideológica precisa entrar em desuso, uma vez que a defesa e a apresentação de ideologia de um movimento "revolucionário" tão só nutrem o sistema operatório simulador com possíveis atuações aplicáveis aos que se tornam contraposição ao capital.

Baudrillard chega a afirmar que a luta sustentada por dispêndio de energia, planejamentos calculantes e racionais a fim de que o poder político se torne posse da micropolítica, cai em uma espécie de Anel de Möbius, isto é, em um eterno círculo volteante em que nada surte efeitos revolucionários. A guerra sustentada no plano real (horizonte das representações/presenças), mesmo criando a maior violência contra o sistema, não chega sequer minimamente agredi-lo. A verdadeira agressão, na ótica de Baudrillard, não está, reciprocamente, em dar a devida resposta à violência simbólica 
do capital, mas violentá-lo sem respondê-lo, deixá-lo sem referências na estranheza do derretimento, na flutuação aporética e irresoluta.

$\mathrm{O}$ que faz um sistema reagir se não tem motivos para tal? $\mathrm{O}$ que permite uma contraproposta se precedentemente nada foi proposto? O que seria mais eficaz em uma guerra: uma inócua resposta esperada ou um silêncio movediço e desolador para aquele que aguarda, ardentemente, a réplica a fim de atuar em cooptação? Se essas indagações foram feitas, é sinal de que estamos pensando signicamente e se não há esta postura, salienta Baudrillard (1996, p. 50, grifo do autor), "Jamais venceremos o sistema no plano real" (On ne vaincra jamais le système sur le plan réel). Exacerbar este plano significa se deslocar para o prisma simbólico, impor desafio e ficção como exercício patafísico corruptor de soluções dadas; instaurar uma lógica simbólica sem forças reais a partir da qual o sistema receba dádiva flutuante (resposta nula), deparando-se com o desafio: a morte de qualquer referencial. A nulidade da resposta nada diz ao sistema e não o mune para uma contradádiva (resposta eficaz ao problema). Não há hermenêutica possível e, por isso, não há predicação correta. Trata-se da sinalética que cria uma armadilha contra o capital, este que não tem soluções suficientes para a guerra que se apresenta. O sistema passa a se escorpionizar, dado que o seu mecanismo de domínio fundamental volta contra si. Assim, uma hora ou outra ele cometerá o suicídio, isto é, morrerá na troca com o real porque não pode decifrar e solucionar o desafio que se faz presente em caráter simbólico.

Quer-se revolução? Ela não é impossível, mas pode ser se o projeto dos "revolucionários" ficar situado em marcadores ou em referenciais de libertação que apenas facilitam a sua incorporação ao aparelho modulador do código. Isso representa a ideia de que, se os movimentos micropolíticos buscam, de fato, fazer furos contundentes na macropolítica imperante, eles precisam se elevar à superioridade sinalética, nível sígnico ao qual o capital já se emparelhou. Esse raciocínio de Baudrillard faz pensar que movimentos de esquerda, extremamente pautados em representações, determinações, valores concretos sem o mínimo de imagética que suplante o dado empírico, há muito tempo foram ultrapassados e domados pelo sistema operatório do código capitalista. Sem assumir o que Baudrillard chama de "tipo lógico superior" de atuação (patafísica), não há guerra sígnica.

Guerra sígnica intenciona utilizar a lógica do sistema contra ele mesmo. Fazê-lo sentir a arreferencialidade que tanto promove à heteronomia. $\mathrm{O}$ combate precisa gerar derretimento, aleatoriedade e impossibilidade de assimilação de resposta ao capital. A guerra só é guerra a partir da pungência sinalética, o que implica em subversão, desorientação, distorção de sentidos, a morte como exterminação simbólica. Nos termos de Baudrillard:

[...] é preciso ir mais longe do que o sistema na simulação. É preciso lançar a morte contra a morte - tautologia radical. Fazer da própria lógica do sistema a arma absoluta. Contra uma sistema hiper-realista, a única estratégia é patafísica, de algum modo "uma ciência das soluções imaginárias", isto é, uma ficção científica do retorno do sistema contra si mesmo, no limite extremo da simulação, de uma simulação reversível numa hiperlógica da destruição e da morte (BAUDRILLARD, 1996, p. 11).

Morte traz a perspectiva de abalo simulador que a patafísica (lógica hiperrealista) gera no sistema. Por isso se dá como tautologia radical, uma vez que Baudrillard busca fazer da raiz fortalecedora do código a sua principal homicida. A semiocracia passa a se tornar arma necessária como antissistema. Aí a importância da patafísica, já que este é o elemento decisório para se criar soluções que vão além do atual, permitindo-se propostas arreferenciais desacopladas da atualidade empírica.

Por que a patafísica se torna preponderante nesta guerra? Eis os seus propósitos: 
1. fazer do fármaco sistêmico um veneno com alto grau de nocividade contra si mesmo;

2. Impossibilitar a assimilação, a manipulação ou a desintegração da ficção insurgente; 3. lançar o capital na indeterminação, causar o que Baudrillard chama de curto-circuito: um sistema sem orientação para não confrontar atuações antitéticas, uma vez que nem mesmo ele assimilará informações ou respostas.

No pólemos patafísico, não há diálogo ou resposta do movimento hiperrealista/simulador. Retira-se da zona de representações calculantes com vínculos na atualidade. A patafísica produz um tipo de violência sígnica que passa ao largo de presenças ou referenciais tão valorizados por movimentos micropolíticos. Ela se dá como uma contra-hermenêutica, tendo-se em vista que intenciona destruir sentidos petrificados na lógica dos marcadores. Assim, anuncia Baudrillard (1996, p. 11, grifos do autor): "Uma reversibilidade minuciosa, eis a obrigação simbólica. Que cada termo seja ex-terminado, que o valor seja abolido nessa revolução do termo sobre si mesmo essa é a única violência simbólica equivalente e triunfante diante da violência estrutural do código". Fica claro, então, que violentar ("signizar") o sistema com a sua própria estrutura flutuante, por meio de simulação, é uma forma possível de guerrilhar contra o capital. Para Baudrillard, a patafísica é máquina de guerra em tempos de flutuações sociopolíticas como meio mais eficaz de confronto do que as lutas libertárias de movimentos "sublevadores".

\section{O caso Haia}

Vejamos, para entendermos melhor como a guerra sígnica se dá, o caso Haia. Quando terroristas invadem uma instituição e tomam reféns, a lógica real calcula que logo farão suas exigências e o especialistas em negociação tentarão resolver o problema que se apresenta, esperando saber qual é a troca que os terroristas desejam. Os negociadores buscam chegar a uma situação de equivalência, que seria a liberação dos sequestradores após a libertação dos reféns. A negociação, nesse cenário, é representativa, pois traz presente uma comutação por correspondência que não está na ordem sígnica e que, portanto, facilita o trabalho dos policiais empenhados na operação. Mas, em Haia, relata Baudrillard, o caso perde resolução real e descamba para o âmbito sinalético. Não é possível negociar concretamente, não se chegando a equivalências, porque os terroristas impossibilitam trocas e lançam os negociadores ao contratempo sígnico: à morte, ao curto-circuito.

Eis o problema: o sistema não dá conta de desafios simbólicos, isto é, ausentes de cálculos e de conciliação. "A essa irrupção do simbólico (que é a coisa mais grave que lhe pode acontecer e, no fundo, a única 'revolução') o sistema não pode, não sabe responder senão pela morte física, a morte real dos terroristas" (BAUDRILLARD, 1996, p. 52). Todavia, quando o fim da operação descamba à morte concreta, o sistema mesmo decai à dimensão do real. $\mathrm{O}$ desafio foi sígnico, mas a solução foi liderada pela resposta física: o assassinato. O simbólico suplantou a via das soluções empíricas do Estado, este que não conseguiu decifrar a des-ordem da ausência de acordo com os terroristas. $\mathrm{O}$ que resta à instituição policial é perder a guerra, matar fisicamente e darse por vencida. A sinalética desafiou, lançou o conflito, mas o sistema não conseguiu superá-lo. "É o que acontece nesse caso: o sistema é encurralado para suicidar-se em troca - o que ele faz manifestamente por sua desorganização e sua derrota" (BAUDRILLARD, 1996, p. 52). Ou seja, a negociação entra em colapso, desorganizase a tal ponto que só resta o suicídio da operação: matar o quanto antes para dar alguma resposta à sociedade que assiste ao caso. O exemplo de Haia demonstra o quanto o Estado entra em curto-circuito (surto quando se depara com o simbólico) e o quanto o pólemos sígnico é mortal para o sistema. Por isso, Baudrillard chega a dizer (1996, p. 
52): "Os caminhos de uma política alternativa são os da eficácia simbólica”.

\section{Greve pela greve}

Trata-se da guerra que assume, como política alternativa, a contundência arreferencial que o desafio sígnico produz no sistema. A greve sinalética não corresponde à greve dos marcadores, esta justificada a partir de arranjos políticos tradicionais que acabam por se desgastar com o tempo. A estimativa de Baudrillard é que esta greve está morta. Além do desgaste que a leva a perder vigência funcional, ela não muda o panorama de violação sígnica do sistema contra os sindicatos. $\mathrm{O}$ máximo que pode ocorrer é a greve arcaica conseguir retirar do capital o que ele, no porvir, já tinha planos de conceder.

Ou a greve se torna forma-signo desafiadora do sistema ou continua em sua luta anacrônica e representacional pronta a exigir trocas e equivalências, mas nada transformar com os seus gastos de energia. A via para uma revolução é outra: "A greve pela greve é a verdade atual da luta. Sem motivação, sem objetivo nem referencial político, ela responde opondo-se a uma produção ela mesma, sem valor de uso social, sem outra finalidade que não ela mesma" (BAUDRILLARD, 1996, p. 39). Porém, o que faria uma greve sem referencial político, ausente de motivações e de objetivos claros contra o que se luta? Para Baudrillard, é justo esta reversão tautológica do sistema contra ele que faz surtir efeitos. A greve pela greve micropolítica se torna insurgente porque assume o papel do capital contra ele mesmo, hiper-realizando-se na produção de resposta-nula, de dádiva vazia e, portanto, assimilando e utilizando o estágio derradeiro da revolução estrutural do valor, que é a dimensão da simulação em prisma de sublevação. Simular ou ficcionar contra o capital se torna a única guerra possível.

O capital centraliza as suas forças para convencer o corpo social que ainda se baseia em condições físicas de poder. Vimos, até aqui, a partir das perspectivas patafísicas de Baudrillard, que essa verdade está inserida em campo movediço de uma simulação. Há tempos o capital é sígnico. A percepção de que ele ascendeu à lógica hiper-real é o que abre sendas para os movimentos sublevadores parodiarem a força sinalética sem fim instituído, gerando derretimentos e flutuações. Assim, não se cria plano, mas reproduz-se um modelo que é justo o da reprodução de sinais que nada deve ao campo físico, porque partem da dimensão do simbólico sem referência ao real.

\section{Os graffiti como liberdade ofensiva}

Vimos que Baudrillard denuncia o ordenamento operacional semiocrático do capital que, por meio da sinalética, põe abaixo a eficácia das revoltas sociais logo cooptadas pelos "modelos de simulação orquestrados" (modèles de simulation orchestrés) (BAUDRILLARD, 1996, p. 101). Todavia, na seção Kool Killer ou a Insurreição pelos Signos (Kool Killer ou L'insurrection par les signes), o referido autor traz à tona outra máquina de guerra sígnica que se contrapõe fortemente à ordem estrutural de valor. Trata-se dos graffiti que produzem inscrições indeslindáveis, matrículas simbólicas ou assinaturas que violam a hermenêutica midiática, a publicidade e as logografias com pretensões de acúmulo de sentidos. São formas-signos impactantes e desconcertantes da escrita coloquial ou formal de uma língua.

Para a filosofia de Baudrillard, os graffiti são transgressores da escrita comum justo porque não buscam representar o mundo fáctico. Apresentam seus carimbos arreferenciais ausentes de conteúdo. Ocorre recessão de significante sem elo ao significado. Representação e valor representado se distanciam. Não há adequação ou 
correção entre o que se grafa com alguma estrutura física. É nesse sentido que não se pode dominar, hermeneuticamente, a arte do dizer vazio dos graffiti, pois só há forma em seus grafismos e não conteúdo. Eles se tornam um modo de semiocracia e o Estado, não podendo dar resposta à flutuação de seus dizeres sígnicos, tem como solução apagar todos os graffiti da cidade que estão nos metrôs e nas paredes dos edifícios. Resposta insuficiente das políticas de limpeza social. O desafio simbólico não foi resolvido e, por isso, no outro dia as assinaturas estão registradas na cidade.

O que rege a cultura dos graffiti é a anonimidade. Aqui não há revelação de identidade muito embora os grafismos estejam repletos de números, endereços e nomes. Mas reunindo todo este arcabouço de signos, o Estado não tem condições de decifrar uma via adequada de como se ler as inscrições feitas pela cidade. Reina a flutuação e a exterminação contra o sistema interpretativo de formas. Pode-se arriscar dizer que a tarefa de interpretar signos gregos ou egípcios de períodos antigos seja menos complexa do que traduzir os graffiti propositalmente geradores de curto-circuito naquele que busca representar sentidos no que nasceu para não ter significado. O produtor da inscrição sem referentes está dentro de sua região de atuação, regido por sua própria lógica, suplantando esquemas organizados. Para deixar claro o que argumentamos aqui, apresentamos a análise de Baudrillard:

SUPERBEE SPIX COLA 139 KOOL CRAZY CROSS 136 não quer dizer nada e sequer é um nome próprio; é uma matrícula simbólica feita para subverter o sistema comum dos nomes [...] como um antidiscurso, recusa de toda elaboração sintática, poética, política como menor elemento radical inapreensível por qualquer discurso organizado (BAUDRILLARD, 1996, p. 102).

A inscrição não pode ser assimilada por qualquer critério hermenêutico externo ao terreno do grafismo totêmico (assinatura do clã ou grupo do qual o sujeito participa). Ela é uma presença nula, um vocativo vazio que não instaura conotação ou denotação, isto é, não traz sentidos figurados e tampouco permite extrair um sentido em elo com a fisicidade do real. No entanto, isso não nega a riqueza das matrículas espalhadas pela cidade. A opulência delas está precisamente ligada à pobreza e irredutibilidade de todo o seu rito sígnico que não pode ser acompanhado pelo ditame comum dos nomes, pois não se dá como código pronto a ser descodificado. Os graffiti representam o que Deleuze chama de "corpo sem órgãos" (corps sans organes), o mecanismo esquizo de nadificação de sentidos e o que Baudrillard salienta como a "liberdade da ofensa" (liberté offensive).

Os graffiti são criados por clãs das periferias da cidade. Eles partem de um território e são estendidos para além de sua regionalidade quando as matrículas codificadas são expostas nos metrôs e nas paredes, podendo ser vistas por todos que passam. As ruas e bairros, além do território do clã, passam a viver a periferia, os centros da cidade branca visualizam as assinaturas indecifráveis do gueto, que começam a se maximizar aos vários cantos da metrópole por causa da violenta repressão do Estado sobre as manifestações dos que são marginalizados. Assim, a cidade passa a ser simbolicamente inscrita pela reação periférica contra a ideologia repressiva. A recessão de conteúdo e o dizer irrepresentável entram em cena.

\section{A guerrilha da desorientação}

A guerra sígnica não tem como prisma violentar o inimigo físicamente. Isso parece já estar claro. Este tipo de guerrilha tem a função de confundir aquele contra o qual se luta. Vimos que os graffiti cumprem bem esse feito para Baudrillard, dado que é a nulidade comunicativa que os tornam intensos. A nadificação sinalética é a forma 
mais significativa de insurreição. Para tanto, elucida o filósofo francês, não é necessário, para isso, organizar um grande grupo de revolucionários a ponto de criar uma massa de guerrilheiros, bem como não se faz necessário uma formação política de alto nível para gerar uma simulação ou hiper-realização que consiga desorientar o inimigo. A perspectiva aqui é de uma violação citadina, um embaralhamento urbano a partir da lógica de desconstrução dos signos que orientam o real. O exemplo de Baudrillard (1996, p. 104) se refere aos "checos [que] mudavam o nome das ruas de Praga para desorientar os russos". Pode haver grande complicação à pessoa quando ela chega a um lugar que não conhece, mas pensa que está situada no local por referência de uma placa que, na verdade, a desorienta já que os sinais da região foram trocados. A partir do texto Simulacros e simulação (Simulacres et simulation, 1981), essa dispersão sígnica é deslindada:

Trata-se de uma substituição no real dos signos do real, isto é, de uma operação de dissuasão de todo o processo real pelo seu duplo operatório, máquina sinalética metaestável, programática, impecável, que oferece todos os signos do real e lhes curto-circuita todas as peripécias (BAUDRILLARD, 1991, p. 9).

A indicação evidencia o quanto a máquina sinalética é um elemento fecundo de guerra, visto que não substitui o real, mas os signos que nele estão inseridos e que orientam, com placas, os nomes das ruas. Os checos contra os russos dissuadem os signos orientadores, permitindo a quebra da estabilidade de localização, o que Baudrillard chama de peripécia de um processo que visa exatamente colapsar o arranjo do mundo sem nele tocar. $\mathrm{O}$ que se transmuta são todos os seus sinais representativos de lugar. $\mathrm{O}$ curto-circuito se instala como consequência da hiper-realização do local, a desolação de estar corrompido pelo lance dos signos embaralhados.

A teleologia sinalética, como se vê, não visa poder físico que violente o corpo do inimigo. Se esse fosse o escopo, o dispêndio da guerrilha seria muito alto. Todavia, em um único esforço de signização do real, a partir da simulação de placas (des)orientadoras, há baixo gasto de capital e de força física já que não se necessita de metralhadoras, granadas ou tanques de guerra. Basta a vontade de um grupo insurgente operar a sinalética para desmanchar a disposição do real, liquidar referenciais e, por conseguinte, correções interpretativas.

Podemos pensar, de modo patafísico (fíccional), como seria embaraçosa a mudança sígnica para aqueles que estão onde não gostariam de estar. No caso de uma mudança de placas da cidade ou na perda de referência quando se vai ao trabalho. Neste último caso, no metrô, itinerários e nomes das estações são trocados, propositalmente, por um grupo de guerrilheiros sinaléticos que querem testar a força da simulação, mas quem é afetado não tem consciência desse fato. Os descaminhos e conturbações são múltiplos e toda vida social dos usuários é afetada. Atraso, desordem, nervosismo, desentendimento do que é real ou hiper-real, tudo isso acontece. Sem dúvida, uma guerra simuladora decorre e desconcerta a rotina das pessoas. O interessante é que, nessa ficção, o real continua o mesmo e apenas os signos sofrem transmutação.

Agora podemos perceber como a ação simbólica pode cumprir trocas que permitam um vazio referencial a ponto de deslocar os seres humanos sem serem de fato deslocados, uma vez que o real continua intocável, mas signicamente embaralhado. "É também o afundamento da realidade no hiper-realismo [...] o real se volatiliza, torna-se alegoria da morte [...] fetichismo do objeto perdido - não mais objeto de representação, mas arrebatamento de recusa e de sua própria exterminação virtual: hiper-real" (BAUDRILLARD, 1996, p. 94). Morte, nesse (des)contexto, significa sinal apartado do real, a virtualidade que faz questão de perder de vista a fisicidade do mundo porque se deleita com a possibilidade de simular para além das presenças sensíveis. A sinalética entre checos e a nossa patafísica que ficcionou as trocas de itinerários no metrô 
elucidam a desconexão entre simulação e representação, entre o virtual e o real.

$\mathrm{O}$ que precisa ficar entendido em Baudrillard é que a composição hiper-real não visa simular para perder realidade, mas tem como pressuposto duplicar o real, reproduzi-lo e inflacioná-lo. Vivemos no hiper-realismo-informativo porque temos reprodução constante de realidades e de informações sem lastro no mundo físico, o que gera, segundo Baudrillard (1996, pp. 95-96), "vertigem de realidade" (vertige de réalité) porque "O hiper-real só está além da representação por estar todo inteiro na simulação", ficcionando para além da ancoragem em presenças.

\section{Anagrama: operação de desmanche da representação}

Baudrillard destaca que Saussure, em suas pesquisas semiológicas, nos Cadernos de anagramas (Cahiers d'anagrammes), descobre uma forma de linguagem não econômica, isto é, que não busca acumular sentidos dados. Ao contrário, a anagramática permite uma comutação de termos que rompe com a acumulação de representações. Ela emerge como linguagem poética que libera uma operação simbólica além da esfera hermenêutica. "No campo de uma antidiscursividade, de um para-além da economia política da linguagem [...] operação de desconstrução do signo e da representação" (BAUDRILLARD, 1996, p. 249).

$\mathrm{O}$ anagrama, por comutar a linguagem com suplementos ao largo da linguística instituída, vai além da presença. Esse ir adiante significa que a troca que é operada na anagramática se torna uma contra-hermenêutica já que impede a recepção não contenciosa das inscrições ou até mesmo elimina qualquer interpretação clarificadora do que está escrito. Um exemplo para melhor compreender o que aqui se diz é a matrícula simbólica expressa pelos graffiti: SUPERBEE SPIX COLA 139 KOOL CRAZY CROSS 136. Pode-se reunir os termos desta inscrição na tentativa de se criar um valor representativo sobre ela, porém, o máximo que se pode saber é que se trata de uma operação sinalética que gera brusca ruptura com a economia hermenêutica (acumulação de sentidos a partir dos termos reunidos na inscrição).

Saussure, segundo Baudrillard, descobre o poder da contraordem linguística, mas não a explora em perspectiva revolucionária. Ele apenas reflete sobre o anagrama para nutrir a ciência linguística a partir de outra forma de linguagem que não é a da reunião de termos e de sentidos, mas a de sua dispersão e desmanche. O escopo de fazer uso dele como modo de insurreição dos termos surge na sinalética política de Baudrillard, o que, de certo modo, já é arma de guerra das periferias com seus graffiti e imagens indecifráveis.

A poética anagramática aparece como uma forma de anti-grammé, um recurso textual para além dos limites da escritura e da fonética usuais ou restritas. Não há configurações vocabulares ou lexicais, coloquiais ou formais, restritas ou universais no poético, "fato de ele violar as "leis fundamentais da palavra humana" e de "nos fazer sair da ordem linear" (BAUDRILLARD, 1996, p. 251). Superar tal ordem implica em cessar o elo entre significante (representação) e seu significado (valor representado). Aniquila-se a linearidade da acoplagem de signos e, assim, revoluciona-se os termos na ausência de correção ou adequação. Rompe-se com a lógica da verdade em conformidade do pensamento à coisa (veritas est adaequatio rei et intellectus). $\mathrm{O}$ poético nada conforma, ao contrário, propicia a dispersão dos termos e, consequentemente, o desmanche interpretativo.

Graças ao potencial anagramático de exterminação de valor, Baudrillard o vê como um elemento de insurreição à medida em que colapsa as inscrições quando os seus termos perdem adequação com o real. A poética anagramática desafia as leis da significação. Ela não é cidadã e nem obedece a uma pátria linguística. Apátrida, não 
encontra equivalente geral, tornando-se uma inscrição antilinear. Sai-se da equivalência linguística e ingressa-se na simulação arreferencial que dispersa termos. Por isso, Baudrillard afirma (1996, p. 252, grifos do autor): "o poético é [...] um processo de exterminação do valor" (le poétique est [...] un processus d'extermination de la valeur). Em outras palavras, o anagrama é homicida da expressão, da hermenêutica e da 116 representação. A morte do valor é a morte do sentido situado.

\section{VALOR, RESTO E POÉTICO}

Quando Baudrillard argumenta sobre valor, o autor pensa em perspectiva econômica: valor como aquilo que surge do resultado de acumulação, produção e distribuição. Quando se aplica recursos em fundos de investimento, por exemplo, gerase valor para baixo ou para cima: acumula-se perdas ou ganhos. É fato que o investidor deseja ter rendimentos positivos. Agora, em prisma semiológico, a partir da vontade de entendimento e assimilação de sentidos, a economia da linguagem investe na acumulação de termos para melhor produzir e distribuir significados. Nesse enfoque, valor linguístico significa, em Baudrillard, o percentual necessário de acúmulo representativo para haver adequação na comunicação. Por isso, "a tentativa desesperada de salvar, ainda que por meio de um jogo mais complexo, a lei do valor linguístico e as categorias essenciais do modo de significação" (BAUDRILLARD, 1996, p. 252). Isso indica o quanto a linguagem habitual, sedenta por representação, decai diante do poético. O seu enlevo só se dá a partir do valor, dos termos economicamente acumulados e situados. A dispersão anagramática parece aborrecer o mundo da cotidianidade média, a existência trivial e, por isso, essencial é concentrar valor e alinhar as palavras para a farta adequação de sentidos.

De um lado, há linguagem habitual com os seus pressupostos: correção dos termos (significantes) para haver adequados valores (significados). De outro lado, temos o anagrama que desmancha essa composição, permitindo outra operação que insurge contra a sintonia da conjunção de termos. Nesse sentido, se o poético extermina valor, é porque "O poético é a insurreição da linguagem contra suas próprias leis" (BAUDRILLARD, 1996, p. 252). O anagrama traz à tona a linguagem contra ela mesma. Eis a guerra do desarranjo sígnico contra a guerra dos sentidos. Nesta atuação simbólica, nomes, significantes, identidades perdem lócus, pois, como salienta Baudrillard (1996, p. 254, grifos do autor), há "exterminação do termo nessa dispersão sem volta", que alimenta o poético no qual não há duração de resto, onde nada resta.

Ausência de resto, para Baudrillard, significa a não acumulação de sentidos. Os graffiti que estampam uma série de palavras, números e imagens propiciam a morte de significantes e significados, isto é, de representações e valores representados. As leis linguísticas nada podem fazer para dar sentido correto ao que as assinaturas simbólicas carimbam nas paredes, porque nada além da inscrição resta. Acumula-se registros, mas não valores ("sentidos"). Não há o que predicar, judicar ou comunicar nos grafemas pela cidade. $\mathrm{O}$ jovem da periferia anagramatizou o real com símbolos dispersos e nem se importou com o resto, com o sentido de sua assinatura.

O resto é o que orienta a linguagem humana, permitindo termos (palavras) adequadamente acoplados para se gerar sentidos claros. O escopo é que textos e falas sejam orientados gramaticalmente para que emissor e destinatário possam se entender. É pelo acúmulo econômico-linguístico de resto que se funda a comunicação. Nas próprias reflexões de Baudrillhad (1996, p. 255, grifos do autor), “O resto é o valor. É o discurso da significação, nossa linguagem regida pela linguística [...]: aí repousa a economia da significação e da comunicação". Reiteramos que econômico, na perspectiva do referido autor, em nada tem relação com moderação de discurso, mas, ao 
contrário, vincula-se à era hiper-informativa, lida com a reprodução indefinida de resto/valor/expressão/sentido.

O hiper-realismo que conjuga hiper-cultura e hiper-informação dissemina termos, expressões e representações, isto é, restos de forma abusiva e sem qualquer responsabilidade sobre o que é despejado no mundo sociovirtual. Trata-se da era da publicidade inconsequente, da livre expressão que, pelo deleite de exposição, maximiza o culto à multiplicidade de imagens, falas, vídeos e diversas outras postagens que engendram o império hiper-linguístico cujo lema podemos traduzir como: "Seja visto, seja ouvido". Esse imperativo que apela para a exposição é tão fecundo que o café da manhã, a cerveja com os amigos ou uma simples peça de roupa adquirida merecem fotos e postagens nas redes sociais com alguma frase trivial que gera significados também comuns, afinal, o que massifica esse tipo de relação social é justo a linguagem econômica, isto é, cheia de resto. Por isso, diz Baudrillard (1996, p. 255, grifos do autor): "Essa 'liberdade' do discurso [...] essa ideia da linguagem como de um meio para tudo fazer e de uma natureza inesgotável [...] da liberdade de um desperdício fantástico - esse estatuto, que é o da nossa comunicação discursiva".

$\mathrm{O}$ resto é resíduo e, em uma sociedade hiperprodutiva, o que mais resta é resto. Isso significa que, em meio a tantas produções "culturais", o interesse não é disseminar a qualidade no real, mas expressões inesgotáveis. A consequência lógica de uma produção exacerbada de linguagem, sem fim qualitativo, é o que Baudrillard (1996, p. 256) chama de "fantástica sedimentação de dejetos, de matéria discursiva opaca [...] essa gigantesca instância residual petrificada". A sociedade da intensa expressão é a que alimenta a era da comunicação dispendiosa. Permite e sustenta o gasto de linguagem para que o "ser visto e ouvido" tenha lugar no que Baudrillard indica como "economia de profusão" (acumulação para prodigalidade). A exuberância de capital linguístico se torna basilar para aquele que quer se publicizar nas redes e, assim, expressa-se para o meio social a partir do dispêndio da palavra. De toda forma, essa profusão, o falatório midiático acaba por gerar o processo de dejeção uma vez que acumula massa superprodutiva de notícias e imagens. Como salienta Chul Han (2017, p. 15), "Baudrillard fala [...] da 'obesidade de todos os sistemas atuais', do sistema de informação, do sistema de comunicação e do sistema de produção". Tal inchaço se dá pelo que comentamos no início deste texto: o excesso de positividade do sujeito que o autoriza a produzir e lançar, para a sociedade de consumo, tudo o que for permitido, isto é, muito resíduo.

$\mathrm{Na}$ obra $A$ sombra das maiorias silenciosas (A L'ombre des Majorités Silencieuses, 1978), Baudrillard tece críticas ao espetáculo dos estereótipos que a lógica da fascinação midiática impulsiona: informação e socialização simplistas às maiorias. “[...] Elas [as massas] querem apenas signos, elas idolatram o jogo de signos e de estereótipos, idolatram todos os conteúdos desde que eles se transformem numa sequência espetacular" (BAUDRILLARD, 1985, pp. 8-9). As massas são mantidas sob um certo ideal de sentido apto a ser assimilado rapidamente. O exemplo que Baudrillard apresenta é o do jogo de futebol que toma a atenção de 20 milhões de espectadores na França enquanto um problema político no país passa ao largo de ter o mesmo número de pessoas atentas $2 \mathrm{x}$.

$\mathrm{O}$ poético, em contraponto à arrumação do palavrório, torna-se símbolo do desmantelamento contra as representações cotidianas da publicidade. $\mathrm{O}$ foro do sentido é estremecido e, desse modo, o habitual da palavra morre. A abertura fundamental do poético está na suspensão da sequência dejeta de comunicação, pois, a partir de suas inscrições, não há o que se decifrar. Como expressa Baudrillard (1996, p. 263), “A irradiação simbólica do poema" (l'irradiation symbolique du poème) é promotora da "intensidade do poético" (l'intensité du poétique), o que não intenciona buscar referentes. A sua força (como os graffiti) não busca representar coisa alguma, mas antes 
chega ao termo vazio, à nulidade do significado. $\mathrm{O}$ falatório opaco sofre a vertigem do zero no poético porque, nostálgico pelo sentido, clama por ordenamento dos termos. Assim, "o modo poético implica estas duas coisas: liquidação do significado e resolução anagramática do significante" (BAUDRILLARD, 1996, p. 264, grifos do autor). Dito de outro modo, a sinalética do poema precisa gerar a morte do valor

118 representado e anagramatizar o significante (representação) para fazer de suas palavras inscrições sem restos ou vestígios, isto é, um significante que nada representa e, por isso, não criar valor de presença (sentido dado).

Pela potência de nulidade que a anagramática poética tem, é justo essa intensidade na desconstrução de valores e sentidos dados que faz Baudrillard pensar os discursos arreferenciais como elementos de insurreição contra o capital. A guerrilha precisa, para revolucionar as ordens instituídas, ser anagramática, produzir trocas simbólicas com o vigor da dispersão poética, que abalem as teleologias e estruturas sistêmicas. É precisamente este o panorama insurgente que cumpre $O$ caso Haia, Greve pela greve, Os graffiti como liberdade ofensiva, A guerrilha da desorientação e o Anagrama: operação de desmanche da representação. Cada forma de insurreição promove trocas de palavras, sinais, inscrições, itinerários ou até mesmo não transparece termo algum. Desloca-se, simbolicamente, da linguagem habitual e dilacera, a partir dessa dispersão anagramática, o poder de resposta do sistema.

$\mathrm{O}$ que o capital pode responder à linguística insurgente se ele nada pode representar de suas violências sígnicas e muito menos ativar soluções para elas? A anagramática é desterritorializante, flutua signos, ofende a estruturação das inscrições e das falas a partir da recessão de conteúdo que ela deixa acontecer. Não se produz resto, resíduo, predicação. Não se acumula sentidos, mas os dispersa fertilmente para além do que se institui como comunicação adequada. Por este motivo, Baudrillard é empático à luta por meio dos signos, porque não se revoluciona lutando contra o real, mas desordenando os signos e os conceitos que o organizam. Isso fica evidente quando, em A troca impossivel (L'Échange impossible, 1999), Baudrillard argumenta (2002, p. 148): "É só libertando a imagem do real que lhe conferiremos a sua potência", pois "o jogo essencial é o de libertar o real de seu princípio de realidade" e, assim, a guerra muda de patamar: atinge níveis sinaléticos e ofensivos ainda não presenciados. Tendose essa perspectiva de luta em vista, o emblema da insurgência está traçado: "a revolução é simbólica ou não é" (BAUDRILLARD, 1996, p. 260).

\section{CONSIDERAÇÕES FINAIS}

Se o leitor acompanhou a abordagem da filosofia patafísica de Baudrillard até estas considerações, notou que a via de reflexão deste artigo partiu da simulação como meio funcional-ficcional de se engendrar o hiper sem lastro no princípio de realidade. Isto se aplica ao trabalho uma vez que, hiper-realizado, torna-se virtual e, como consequência, perde o caráter sucursal, ingressando signicamente na vida particular dos "empregados". Variabilidade de horários, descentralização do processo de trabalho, sujeito autônomo e autogestor de seus negócios demonstram como a era industrial, fabril, metalúrgica perdeu espaço para a ordem semiúrgica não sucursal. O trabalho, como diz Baudrillard, passa a ser anunciado e disseminado nos ambientes privados da vida. As corporações perdem corpo, virtualizam-se, operam e incumbem as pessoas dentro de suas próprias casas. Tanto o consumo como o trabalho se tornam voláteis, pulverizados e o processo hiper-real cresce aceleradamente. Assim, o projeto do sujeito moderno de permitir autonomia e emancipação acontece na contemporaneidade: autogestão trabalhista que implica na submissão do trabalhador às suas ocupações. Nessa ótica, inserimos Chul Han no diálogo e trouxemos a sua perspectiva de uma era 
da hiper-realização do trabalho: a sociedade pós-moderna, altamente positiva (motivada, com iniciativa e desempenho) torna-se uma sociedade do cansaço, assumindo mais labor do que pode aguentar.

A questão é que o capital simula novas formas de trabalho, vida, cultura, política, economia e isso indica que produz mais realidade do que de fato existe. Simular se torna a chave do sistema para desgarrar os signos da existência das coisas. Um exemplo comum é o que os mass media produzem: propagandas que sugerem um real desproporcional ao que verdadeiramente se dá no mundo fáctico. Elas não representam o atual, ao contrário, apartam-se de presenças em simulações (criação de signos) para além do que acontece veridicamente. Portanto, o capital desvirtua o real a partir de virtualizações flutuantes que criam efígies ao público consumidor de imagens e notícias. Surge uma miríade de opções e de perspectivas (hiper-realidades) que perde correspondência com a existência.

Para Baudrillard, se o capital tem o poder dos signos simuladores para criar "realidade" além da conta, os segmentos sublevadores, acoplados em representações com lastro, as têm como base de suas implementações e reivindicações sociopolíticas e, deste modo, são eles mesmos que sustentam o sistema. Em contrapartida, é por meio da desordem linguística, corruptora da semântica dada, alimentada pela dissonância do poético que se pode falar em insurreição eficiente. É importante lembrar que a eficácia da linguagem anagramática sobre a qual tanto discutimos aqui não pode ser mensurada porque é sem-medida. Mas algo pode ser dito: o seu ponto alto se dá na dispersão nulificadora, o que significa dizer que, quanto mais desorienta o buscador de sentidos, mais se torna útil para a insurgência.

A relevância do pensamento baudrillardiano se revela precisamente no seu empenho em apresentar a violência simbólica do capital. Baudrillard consegue ir além de dois comuns problemas de algumas perspectivas de esquerda. Primeiro, ele não decai ao nível denuncista, o que implicaria apenas acusar as arreferencialidades do sistema como veículos de dominação social. Segundo, não se torna um filósofo resignado, porque, na obra $A$ troca simbólica e a morte, apresenta linhas de luta e máquinas de guerra que assumem a liberdade da ofensa e a recessão de conteúdo como reprodução da violência sígnica do capital contra ele mesmo. Ou seja, uma alternativa de insurreição que impõe desafio ao sistema é apresentada por Baudrillard, rompendo com o paradigma dos marcadores. Ele explicita a arte da ficção patafísica, a fecunda criação de mundo possíveis, o jogo das soluções imaginativas. Assim, fica aberta a possibilidade de aplicá-la como práxis do desmanche.

\section{REFERÊNCIAS}

BAUDRILLARD, Jean. O abismo do sentido. In: À sombra das maiorias silenciosas. O fim do social e o surgimento das massas. São Paulo: Brasiliense, 1985.

BAUDRILLARD, Jean. A troca simbólica e a morte. São Paulo: Loyola, 1996.

BAUDRILLARD, Jean. L'échange symbolique et la mort. Paris: Gallimard, 1976.

BAUDRILLARD, Jean. A precessão dos simulacros. In: Simulacros e simulação. Lisboa: Relógios d'água, 1991.

BAUDRILLARD, Jean. A fotografia ou A escrita da luz: literalidade da imagem. In: A troca impossivel. Rio de Janeiro: Nova Fronteira, 2002.

BAUDRILLARD, Jean. A sociedade de consumo. Lisboa: Edições 70, 1995.

HAN, Byung-Chul. Sociedade do cansaço. Petrópolis, RJ: Vozes, 2017.

SÊGA, Christina Pedrazza. O Kitsch e suas dimensões. Brasília: Casa das Musas, 2008.

SILVA, Tomaz Tadeu da. Teoria cultural e educação - Um vocabulário crítico. Belo Horizonte: Autêntica, 2000. 


\section{Notas}

1 Segundo Christina Sêga (2008, p. 15, grifos da autora), em seu texto $O$ Kitsch e suas dimensões, "O termo kitsch se origina do alemão kitschen/verkitschen, significando trapacear, vender alguma coisa em lugar de outra. Ele está estritamente ligado à arte num sentido de negação à autenticidade da obra mediante suas reproduções em séries com finalidades comerciais". Para Baudrillard (1995, p. 114, grifos do autor), em $A$ sociedade de consumo (La Société de Consommation, 1970), "O «kitsch» pode encontrarse em todo lado, tanto no pormenor de determinado objeto como no plano de um grande conjunto, tanto na flor artificial como na fotonovela. Será melhor defini-lo como pseudoobjeto, isto é, como simulação, cópia, objeto fictício e estereótipo, como pobreza de significação real e sobreabundância de signos [...] $\mathrm{O}$ «kitsch» surge como categoria cultural'.

2 Trata-se do ano de 1977, quando a Seleção Francesa joga com a intenção de se classificar para a próxima Copa do Mundo enquanto Klaus Croissant (acusado de auxiliar os componentes do grupo de luta armada Baader-Meinhof (Rote Armee Fraktion - RAF/Fração do Exército Vermelho) é extraditado da França para a Alemanha. Acerca desse acontecimento, Baudrillard questiona (1985, p. 10): "pode-se perguntar: por que após inúmeras revoluções e um século ou dois de aprendizagem política, apesar dos jornais, dos sindicatos, dos partidos, dos intelectuais e de todas as energias postas a educar e a mobilizar o povo, por que ainda se encontram (e se encontrará o mesmo em dez ou vinte anos) mil pessoas para se mobilizar e vinte milhões para ficar "passivas"? - e não somente passivas, mas por francamente preferirem, com toda boa fé e satisfação, e sem mesmo se perguntar por que um jogo de futebol a um drama político e humano?". Para o autor, a simplificação de sentidos que o futebol gera é justo o espetáculo que o público deseja, por isso a exaltação do jogo e a apatia em relação aos dramas sociopolíticos que o país vive. 